\title{
Escovação dentária e o risco de fluorose em crianças
}

\section{Tooth brushing and fluorosis risk in children}

Henrique Kunio Sato*

Célia Cristina Fornaziero*

Luiz Reynaldo de Figueiredo Walter **

SATO, H. K.; FORNAZIERO, C. C.; WALTER, L. R. de F. Escovação Dentária e o Risco de Fluorose em Crianças. Semina, Londrina, v. 18, ed. especial, p. 07-14, fev. 1997.

RESUMO: O presente estudo verificou que a média de ingestão de pasta dental usada é baixa, variando de 119 a $226 \mathrm{mg}$. Com base nesses achados, verificamos que o consumo de flúor é relativamente alto e proporcional à concentração de flúor nas pastas existentes no mercado, e que o risco de overdose crônica varia na relação não só do flúor da pasta, como também da frequência de escovação e do flúor no Sistema Público das Águas de Abastecimento. Conclui-se que para até 2 escovações/dia, as pastas de até 1200 PPM não apresentam nenhum risco para as crianças que vivem em cidades sem flúor nas águas, mas que já apresentam problemas para aquelas que vivem em cidades com flúor. Os demais resultados analisados, tanto pela tabela de suplementação da Associação Dentária Americana (ADA), 1995, como pela dose ideal de flúor/peso/dia (STEWART et al., 1982), mostram que as pastas de 1450 e 1500 PPM não podem ser usadas em crianças de 2 a 5 anos, pois a ingestão do flúor via pasta dental ultrapassa o limite de segurança. Talvez este seja um dos fatores que tenha contribuído para o aparecimento de fluorose dentária questionável ou leve na nossa população.

PALAVRAS-CHAVE: Flúor; Fluorose; Escovação Dentária; Pasta Dental; Ingestão de Flúor; Crianças.

ABSTRACT: The present study showed that the average of toothpaste ingestion was low, varying from 119 to $226 \mathrm{mg}$. However, based on these results the consumption of fluoride was relatively high and proportional to the concentration of fluoride in the existing

\footnotetext{
* Autores: Alunos do $5^{\circ}$ ano de Graduação em Odontologia da Universidade Estadual de Londrina.

** Orientador: Livre-docente, Doutor em Odontopediatria/Professor Titular de Odontopediatria da Universidade Estadual de Londrina/Centro de Ciências da Saúderua Pernambuco, 540 - Fone (043) 321-2012 - CEP 86020-070) - Londrina - Paraná.
} 
ioothpaste. The chronicle overdose risk varies with the fluoride in the toothpaste and in the Public System of Water Supply and with the tooth brushing frequency. It was concluded that up to two toothbrushings a day, toothpaste with 1200 PPM does not produce any chronicle overdose risk in children who live in cities without fluoride in the water supply. However, children in cities with fluoride in the water supply can have problems. According to the American Dental Association (ADA) 1995 fluoride supplementary table and to the daily dose of fluoride (STEWART et al., 1982), the toothpaste with 1450 PPM can not be used by children aged 2 to 5 years because the ingestion of fluoride was above the safety limit. Perhaps this fact has contributed to the suspected or slight incidence of fluorosis in our population.

KEY WORDS: Fluoride; Fluorosis; Tooth Brushing; Toothpaste; Fluoride Ingestion; Children.

\section{INTRODUCÃO}

Uma das preocupações atuais em relação ao uso do flúor em Odontologia, por incrível que pareça, não está relacionado com seus efeitos positivos e sim com a intercorrência de um efeito negativo: a "fluorose dentária".

A fluorose dentária tem crescido muito nos últimos anos e segundo EKSTRAND, 1994, a fluorose poderia estar associada à recomendação freqüente de suplementação de flúor, como também, segundo LEVME (1991), pelo uso regular de dentifrício com flúor associado a essa suplementação e/ou a fluoretação de abastecimento de água, podendo assim, contribuir com o risco de uma overdose.

Baseado tanto pela tabela de suplementação de flúor preconizada pela Associação Dentária Americana (ADA) 1995 c pela dose ideal de flúor/dia que é de $0,05 \mathrm{mg} / \mathrm{kg}$ (STEWART et al., 1982), este estudo procurará analisar a relação existente entre o flúor consumido ou não pelas crianças maiores de 2 anos e meio (abastecimento de água e/ou suplementação), com o possível flúor ingerido após as escovações dentárias.

\section{OBDETIVOS}

Este trabalho tem como objetivos:

1) Determinar a quantidade de flúor ingerido por escovação em crianças maiores de 2 anos e meio.

2) Avaliar a margem de segurança de ingestão de flúor nas diferentes freqüências de escovação.

2.1- em crianças que moram em cidades com flúor no Sistema de abastecimento de águas.

2.2- em crianças que moram em cidades sem flúor no Sistema de abastecimento de água.

\section{POPULACAOE MRETODOS}

Foram utilizadas 39 crianças, de ambos os sexos, com idade variando entre 2 anos e meio a 5 anos e meio, que utilizaram escovas e pastas dentais de uso costumeiro e caseiro, sendo que a colocação da pasta foi feita pelo conjunto pais/crianças, sem a intervenção do Cirurgião- 
Dentista.

Todas as crianças foram pesadas em uma balança antropométrica marca FILIZOLA, a fim de se obter o peso corporal.

Para a pesagem das escovas utilizamos uma balança eletrônica de precisão GEHAKA - BG 200, onde foram realizados:

1) Peso da escova seca. (P1)

2) Peso da escova embebida com saliva. (P2)

3) Peso da escova embebida com saliva + Pasta dental. (P3)

4) Peso da escova após a escovação. (P4)

\section{RESULTADOS E DISCUSSÃO}

A quantidade de pasta ingerida durante a escovação foi calculada através da diferença entre P3 e P4 (escova embebida e com resíduos).

Após a determinação da quantidade de pasta em mg, estabeleceu-se a quantidade de flúor ingerido para cada pasta nas suas diferentes concentrações: 1000, 1100, 1200,1450 e 1500 PPM.

Para facilitar separamos a população em 3 grupos de acordo com o peso corporal:

$1^{\circ}$ grupo) $<15 \mathrm{~kg}$

$2^{\circ}$ grupo) 15 a $20 \mathrm{~kg}$

$3^{\circ}$ grupo) 20 a $25 \mathrm{~kg}$

Para cada grupo de peso, relacionamos a concentração de flúor nas pastas com a quantidade de flúor ingerido durante a escovação e após essas determinações foi calculado o flúor teoricamente ingerido em 2 situações possíveis:

1) cidades com flúor no Sistema de abastecimento de água.

2) cidades sem flúor no Sistema de abastecimento de água.

Na situação 1 adiciona-se 0,25 mg de flúor/dia, que é a média ingerida por crianças nessa faixa etária, segundo dados da Associação Dentária Americana (ADA) 1995, na situação 2 , não se adiciona flúor/dia.

Para verificação da freqüência de escovação, separamos as crianças em 3 grupos:
1) crianças que escovam até 2 vezes ao dia

2) crianças que escovam 3 a 4 vezes ao dia

3) crianças que escovam mais de 4 vezes ao dia.

Verificamos que a média de ingestão de pasta foi baixa, nos diferentes grupos de peso, sendo que a ingestão foi menor nas crianças de menor peso e maior nas de maior peso.

$1^{\circ}$ grupo: $119 \mathrm{mg}$

$2^{\circ}$ grupo: $215 \mathrm{mg}$

$3^{\circ}$ grupo: $226 \mathrm{mg}$

Com base nesses dados, verificamos que o consumo de flúor é relativamente alto e proporcional à concentração de flúor existente nas pastas encontradas no mercado e que o risco da ocorrência de overdose crônica varia na relação, não só do flúor existente na pasta, como também da frequência de escovação diária e da existência ou não de flúor no Sistema de abastecimento de água.

Para o $1^{\circ}$ grupo (crianças até $15 \mathrm{~kg}$ ), em uma frequência de escovação de 2 vezes ao dia, segundo os parâmetros de suplementação de flúor preconizado pela ADA, todas as pastas dentais estudadas podem ser usadas em cidades sem flúor na água; sendo que nas cidades com flúor na água, apenas as pastas de 1000 e 1100 PPM podem ser usadas (Quadro 1). No entanto quando tomamos por base a dose ideal de ingestão diária de flúor proposta por STEWART $(0,05 \mathrm{mg} / \mathrm{kg}$ de peso corporal), todas as pastas podem ser usadas nas duas situações, sem restrições (Quadro 2).

Quando observamos a freqüência de 4 vezes ao dia, pelos parâmetros da ADA, as pastas de 1000 e 1100 PPM podem ser usadas pelas crianças que moram nas cidades sem flúor na água, e nenhuma pasta pode ser usada nas cidades com flúor na água (Quadro 3). Pela dose ideal de STEWART, as pastas de 1000, 1100 e 1200 PPM podem ser usadas pelas crianças que moram nas cidades sem flúor na água e nenhuma pasta deve ser usada nas cidades com flúor na água (Quadro 4).

Para o $2^{\circ}$ grupo (crianças de 15 a $20 \mathrm{~kg}$ ), em uma frequência de escovação de 2 vezes ao dia, pelos parâmetros da ADA, as pastas de 1000,1100 e 1200 PPM podem ser usadas pelas crianças nas cidades sem flúor na água e nenhuma pasta deve ser usada nas cidades 
com flúor na água (Quadro 5). Pela dose ideal de STEWART, apenas a pasta de 1500 PPM não deve ser usada nas cidades com flúor na água (Quadro 6).

Ainda para o $2^{\circ}$ grupo, em uma frequência de 4 vezes ao dia, pelos parâmetros da ADA, nenhuma pasta deve ser usada pelas crianças que moram nas cidades com e sem flúor na água (Quadro 7). Pela dose ideal de STEWART, as pastas de 1000 e 1100 PPM podem ser usadas nas cidades sem flúor na água (Quadro 8).

Para o $3^{\circ}$ grupo (crianças de 20 a $25 \mathrm{~kg}$ ), em uma frequência de escovação de 2 vezes ao dia, pelos parâmetros da ADA, as pastas de 1000, 1100 e 1200 PPM podem ser usadas pelas crianças nas cidades sem flúor na água e nenhuma pasta deve ser usada nas cidades com flúor na água (Quadro 9). Pela dose ideal de STEWART, praticamente todas as pastas podem ser usadas nas duas situações (Quadro 10).

Ainda para o $3^{\circ}$ grupo, em uma frequência de escovação de 4 vezes ao dia, pelos parâmetros da ADA, nenhuma pasta deve ser usada nas duas situações (Quadro 11); e pela dose ideal de STEWART, as pastas de 1000,1100 e 1200 PPM podem ser usadas nas cidades sem flúor na água, e nenhuma pasta pode ser usada nas cidades com flúor na água (Quadro 12).

TABELA 1 - Peso médio, quantidade média de pasta usada e ingerida por escovação, nos grupos; BebêClínica, 1996.

\begin{tabular}{ccccc}
\hline Grupos & Peso (kg) & $\begin{array}{c}\text { Pasta usada } \\
\text { por } \\
\text { escovação }(\mathrm{mg})\end{array}$ & $\begin{array}{c}\text { Pasta ingerida } \\
\text { por } \\
\text { escovação }\end{array}$ & $\begin{array}{c}\text { Pasta ingerida } \\
\text { por } \\
\text { escovação }\end{array}$ \\
\hline $1^{\circ}$ & 13,193 & 308 & 119 & 9 \\
\hline $2^{\circ}$ & 16,800 & 420 & 215 & 12 \\
\hline $3^{\circ}$ & 21,183 & 492 & 226 & 10 \\
\hline
\end{tabular}

TABELA 2 - Média de flúor ingerido por escovação para as diferentes pastas, no $1^{\circ}$ grupo; Bebê-Clínica, 1996.

\begin{tabular}{lcc}
\hline Tipo de Pasta & $\begin{array}{c}\text { Flúor ingerido } \\
\text { por escovação }(\mathrm{mg} / \mathrm{kg})\end{array}$ & $\begin{array}{c}\text { Flúor ingerido } \\
\text { por escovação }\end{array}$ \\
\hline 1000 PPM & 0,009 & 0,11 \\
\hline 1100 PPM & 0,009 & 0,11 \\
\hline 1200 PPM & 0,010 & 0,13 \\
\hline 1450 PPM & 0,013 & 0,17 \\
\hline
\end{tabular}

TABELA 3 - Média de Flúor ingerido por escovação para as diferentes pastas, no $2^{\circ}$ grupo; Bebê-Cínica, 1996.

\begin{tabular}{lcc}
\hline Tipo de Pasta & $\begin{array}{c}\text { Flúor ingerido } \\
\text { por escovação }(\mathrm{mg} / \mathrm{kg})\end{array}$ & $\begin{array}{c}\text { Flúor ingerido } \\
\text { por escovação (mg) }\end{array}$ \\
\hline $1000 \mathrm{PPM}$ & 0,012 & 0,20 \\
\hline $1100 \mathrm{PPM}$ & 0,013 & 0,21 \\
\hline $1200 \mathrm{PPM}$ & 0,014 & 0,23 \\
\hline $1450 \mathrm{PPM}$ & 0,017 & 0,28 \\
\hline $1500 \mathrm{PPM}$ & 0,018 & 0,30 \\
\hline
\end{tabular}

TABELA 4 - Média de Flúor ingerido por escovação para as diferentes pastas, no $3^{\circ}$ grupo; Bebê-Clínica, 1996.

\begin{tabular}{lcc}
\hline Tipo de pasta & $\begin{array}{c}\text { Flúor ingerido } \\
\text { por escovação }(\mathrm{mg} / \mathrm{kg})\end{array}$ & $\begin{array}{c}\text { Flúor ingerido } \\
\text { por escovação }(\mathrm{mg})\end{array}$ \\
\hline $1000 \mathrm{PPM}$ & 0,010 & 0,21 \\
\hline $1100 \mathrm{PPM}$ & 0,011 & 0,23 \\
\hline $1200 \mathrm{PPM}$ & 0,012 & 0,25 \\
\hline $1450 \mathrm{PPM}$ & 0,014 & 0,29 \\
\hline $1500 \mathrm{PPM}$ & 0,015 & 0,31 \\
\hline
\end{tabular}

QUADRO $\mathbb{1}$ - Frequência de escovação de 2 vezes ao dia para o $1^{\circ}$ grupo em relação aos parâmetros da ADA 1995.

\begin{tabular}{|c|c|c|c|c|}
\hline Tipo de Pasta & $\begin{array}{l}\text { Média de Flúor } \\
\text { ingerido por }\end{array}$ & $\begin{array}{c}\text { Freqüência de } 2 \\
\text { vezes ao dia }\end{array}$ & $\begin{array}{l}\text { Flúor recomendado } \\
\text { pela ADA }\end{array}$ & $\begin{array}{l}\text { Pode } \\
\text { escovar }\end{array}$ \\
\hline \multirow[t]{2}{*}{1000 PPM } & 0,11 & 0,22 & 0,50 & SIM \\
\hline & & $0,47 *$ & & SIM \\
\hline \multirow[t]{2}{*}{1100 PPM } & 0,11 & 0,22 & 0,50 & SIM \\
\hline & & $0,47 *$ & & SIM \\
\hline \multirow[t]{2}{*}{1200 PPM } & 0,13 & 0,26 & 0,50 & SIM \\
\hline & & $0,51 *$ & & NÃO \\
\hline \multirow[t]{2}{*}{1450 PPM } & 0,17 & 0,34 & 0,50 & SIM \\
\hline & & $0,59 *$ & & NÃO \\
\hline \multirow[t]{2}{*}{$1500 \mathrm{PPM}$} & 0,17 & 0,34 & 0,50 & SIM \\
\hline & & $0,59 *$ & & NÃO \\
\hline
\end{tabular}

OBS: Os valores com * são para as cidades com flúor no sistema de abastecimento das águas. Foi acrescentado $0,25 \mathrm{mg}$ de flúor. 
QUADRO 2 - Frequência de escovação de 2 vezes ao dia para o $1^{\circ}$ grupo em relação a dose ideal proposta por STEWART 1983.

\begin{tabular}{ccccc}
\hline $\begin{array}{c}\text { Tipo de Pasta } \\
\text { Média de Flúor } \\
\text { ingerido por } \\
\text { escovação (ng) }\end{array}$ & $\begin{array}{c}\text { Frequência de 2 } \\
\text { vezes ao dia }\end{array}$ & $\begin{array}{c}\text { Flúor recomendado } \\
\text { por } \\
\text { STEWART }\end{array}$ & $\begin{array}{l}\text { Pode } \\
\text { escovar }\end{array}$ \\
\cline { 3 - 5 } 1000 PPM & 0,11 & 0,22 & 0,65 & SIM \\
& & $0,47^{*}$ & & SIM \\
\hline 1100 PPM & 0,11 & 0,22 & 0,65 & SIM \\
& & $0,47^{*}$ & & SIM \\
\hline 1200 PPM & 0,13 & 0,26 & 0,65 & SIM \\
& & $0,51^{*}$ & & SIM \\
\hline 1450 PPM & 0,17 & 0,34 & 0,65 & SIM \\
& & $0,59^{*}$ & & SIM \\
\hline 1500 PPM & 0,17 & 0,34 & 0,65 & SIM \\
& & $0,59^{*}$ & & SIM \\
\hline
\end{tabular}

OBS: Os valores com* são para as cidades com flúor no sistema de abastecimento das águas. Foi acrescentado $0,25 \mathrm{mg}$ de fluor.

QUADRO 3 - Frequência de escovação de 4 vezes ao dia para o $1^{\circ}$ grupo em relação aos parâmetros da ADA 1995.

\begin{tabular}{ccccc}
\hline $\begin{array}{c}\text { Tipo de Pasta } \\
\text { ingerido por } \\
\text { escovação (mg) }\end{array}$ & $\begin{array}{c}\text { Méde Flúor } \\
\text { vezes ao dia }\end{array}$ & $\begin{array}{c}\text { Flúor recomendado } \\
\text { pela ADA }\end{array}$ & $\begin{array}{c}\text { Pode } \\
\text { escovar }\end{array}$ \\
\hline 1000 PPM & 0,11 & 0,44 & 0,50 & SIM \\
& & $0,69^{*}$ & & NÃO \\
\hline 1100 PPM & 0,11 & 0,44 & 0,50 & SIM \\
\hline 1200 PPM & 0,13 & 0,52 & 0,50 & NÃO \\
& & $0,77^{*}$ & & NÃO \\
\hline 1450 PPM & 0,17 & 0,68 & 0,50 & NÃO \\
& & $0,93^{*}$ & & NÃO \\
\hline 1500 PPM & 0,17 & 0,68 & 0,50 & NÃO \\
& & $0,93^{*}$ & & NÃO \\
\hline
\end{tabular}

OBS: OS valores com * são para as cidades com flúor no sistema de abastecimento das águas. Foi acrescentado 0,25 mg de flúor.
QUADRO 4 - Frequência de escovação de 4 vezes ao dia para $01^{\circ}$ grupo em relação a dose ideal proposta por STEWART 1983.

\begin{tabular}{lcccc}
\hline $\begin{array}{c}\text { Tipo de Pasta } \\
\text { ingédia de Flúor } \\
\text { escovação (mg) }\end{array}$ & $\begin{array}{c}\text { Frequência de } 4 \\
\text { vezes ao dia }\end{array}$ & $\begin{array}{c}\text { Flúor recomendado } \\
\text { por } \\
\text { STEWART }\end{array}$ & $\begin{array}{c}\text { Pode } \\
\text { escovar }\end{array}$ \\
\hline 1000 PPM & 0,11 & 0,44 & 0,65 & SIM \\
& & $0,69 *$ & & NÃO \\
\hline 1100 PPM & 0,11 & 0,44 & 0,65 & SIM \\
\hline 1200 PPM & 0,13 & 0,52 & 0,65 & SIM \\
& & $0,77^{*}$ & & NÃO \\
\hline 1450 PPM & 0,17 & 0,68 & 0,65 & NÃO \\
& & $0,93^{*}$ & & NÃO \\
\hline 1500 PPM & 0,17 & 0,68 & 0,65 & NÃO \\
& & $0,93^{*}$ & & NÃO \\
\hline
\end{tabular}

OBS: Os valores com * são para as cidades com flúor no sistema de abastecimento das águas. Foi acrescentado $0,25 \mathrm{mg}$ de flúor.

QUADRO 5 - Frequência de escovação de 2 vezes ao dia para o $2^{\circ}$ grupo em relação aos parâmetros da $\mathrm{ADA}$ 1995.

\begin{tabular}{|c|c|c|c|c|}
\hline Tipo de Pasta & $\begin{array}{l}\text { Média de Flúor } \\
\text { ingerido por } \\
\text { escovação (mg) }\end{array}$ & $\begin{array}{c}\text { Frequiência de } 2 \\
\text { vezes ao dia }\end{array}$ & $\begin{array}{l}\text { Flúor recomendado } \\
\text { pela ADA }\end{array}$ & $\begin{array}{l}\text { Pode } \\
\text { escovar }\end{array}$ \\
\hline \multirow[t]{2}{*}{1000 PPM } & 0,20 & 0,40 & 0,50 & SIM \\
\hline & & $0,65^{*}$ & & NÃO \\
\hline \multirow[t]{2}{*}{1100 PPM } & 0,21 & 0,42 & 0,50 & SIM \\
\hline & & $0,67 *$ & & NÃO \\
\hline \multirow[t]{2}{*}{$1200 \mathrm{PPM}$} & 0,23 & 0,46 & 0,50 & SIM \\
\hline & & $0,71 *$ & & NÃO \\
\hline \multirow[t]{2}{*}{1450 PPM } & 0,28 & 0,56 & 0,50 & NÃO \\
\hline & & $0,81 *$ & & NÃO \\
\hline \multirow[t]{2}{*}{1500 PPM } & 0,30 & 0,60 & 0,50 & NÃO \\
\hline & & $0,85 *$ & & NÃO \\
\hline
\end{tabular}

OBS: Os valores com * são para as cidades com flúor no sistema de abastecimento das águas. Foi acrescentado $0,25 \mathrm{mg}$ de fluor. 
QUADRO 6 - Frequência de escovação de 2 vezes ao dia para o $2^{\circ}$ grupo em relação a dose ideal proposta por STEWART 1983; Bebê-Clínica, 1996.

\begin{tabular}{ccccc}
\hline $\begin{array}{l}\text { Tipo de Pasta } \\
\text { Média de Flúor } \\
\text { ingerido por } \\
\text { escovação (mg) }\end{array}$ & $\begin{array}{c}\text { Frequência de 2 2 } \\
\text { vezes ao dia }\end{array}$ & $\begin{array}{c}\text { Flúr recomendado } \\
\text { por } \\
\text { STEWART }\end{array}$ & $\begin{array}{c}\text { Pode } \\
\text { escovar }\end{array}$ \\
\hline 1000 PPM & 0,20 & 0,40 & 0,84 & SIM \\
& & $0,65^{*}$ & & SIM \\
\hline 1100 PPM & 0,21 & 0,42 & 0,84 & SIM \\
& & $0,67^{*}$ & & SIM \\
\hline 1200 PPM & 0,23 & 0,46 & 0,84 & SIM \\
& & $0,71^{*}$ & & SIM \\
\hline 1450 PPM & 0,28 & 0,56 & 0,84 & SIM \\
& & $0,81^{*}$ & & SIM \\
\hline 1500 PPM & 0,30 & 0,60 & 0,84 & SIM \\
& & $0,85^{*}$ & & NÃO
\end{tabular}

OBS: OS valores com * são para as cidades com flúor no sistema de abastecimento das águas. Foi acrescentado $0,25 \mathrm{mg}$ de flúor.

QUADRO 7 - Frequência de escovação de 4 vezes ao dia para o $2^{\circ}$ grupo em relação aos parâmetros da ADA 1995; Bebê-Clínica, 1996.

\begin{tabular}{|c|c|c|c|c|}
\hline Tipo de Pasta & $\begin{array}{l}\text { Média de Flúor } \\
\text { ingerido por } \\
\text { escovação (mg) }\end{array}$ & $\begin{array}{c}\text { Frequiência de } 4 \\
\text { vezes ao dia }\end{array}$ & $\begin{array}{c}\text { Flúor recomendado } \\
\text { por } \\
\text { STEWART }\end{array}$ & $\begin{array}{l}\text { Pode } \\
\text { escovar }\end{array}$ \\
\hline \multirow[t]{2}{*}{1000 PPM } & 0,20 & 0,80 & 0,50 & NÃO \\
\hline & & $1,05^{*}$ & & NÃO \\
\hline \multirow[t]{2}{*}{$1100 \mathrm{PPM}$} & 0,21 & 0,84 & 0,50 & NÃO \\
\hline & & $1,09^{*}$ & & NÃO \\
\hline \multirow[t]{2}{*}{$1200 \mathrm{PPM}$} & 0,23 & 0,92 & 0,50 & NÃO \\
\hline & & $1,17 *$ & & NÃO \\
\hline \multirow[t]{2}{*}{$1450 \mathrm{PPM}$} & 0,28 & 1,12 & 0,50 & NÃO \\
\hline & & $1,37^{*}$ & & NÃO \\
\hline \multirow[t]{2}{*}{$1500 \mathrm{PPM}$} & 0,30 & 1,20 & 0,50 & NÃO \\
\hline & & $1,45^{*}$ & & NÃO \\
\hline
\end{tabular}

OBS: Os valores com * são para as cidades com flúor no sistema de abastecimento das águas. Foi acrescentado $0,25 \mathrm{mg}$ de flúor.
QUADRO 8 - Frequência de escovação de 4 vezes ao dia para o $2^{\circ}$ grupo em relação a dose ideal proposta por STEWART 1983; Bebê-Clínica, 1996.

\begin{tabular}{|c|c|c|c|c|}
\hline Tipo de Pasta & $\begin{array}{l}\text { Média de Flúor } \\
\text { ingerido por } \\
\text { escovação (mg) }\end{array}$ & $\begin{array}{c}\text { Frequiência de } 4 \\
\text { vezes ao dia }\end{array}$ & $\begin{array}{c}\text { Flúor recomendado } \\
\text { por } \\
\text { STEWART }\end{array}$ & $\begin{array}{l}\text { Pode } \\
\text { escovar }\end{array}$ \\
\hline \multirow[t]{2}{*}{1000 PPM } & 0,20 & 0,80 & 0,84 & SIM \\
\hline & & $1,05^{*}$ & & NÃO \\
\hline \multirow[t]{2}{*}{1100 PPM } & 0,21 & 0,84 & 0,84 & SIM \\
\hline & & $1,09 *$ & & NÃO \\
\hline \multirow[t]{2}{*}{$1200 \mathrm{PPM}$} & 0,23 & 0,92 & 0,84 & NÃO \\
\hline & & $1,17 *$ & & NÃO \\
\hline \multirow[t]{2}{*}{1450 PPM } & 0,28 & 1,12 & 0,84 & NÃO \\
\hline & & $1,37 *$ & & NÃO \\
\hline \multirow[t]{2}{*}{1500 PPM } & 0,30 & 1,20 & 0,84 & NÃO \\
\hline & & $1,45^{*}$ & & NÃO \\
\hline
\end{tabular}

OBS: Os valores com * são para as cidades com flúor no sistema de abastecimento das águas. Foi acrescentado $0,25 \mathrm{mg}$ de flúor.

QUADRO 9 - Frequência de escovação de 2 vezes ao dia para o $3^{\circ}$ grupo em relação aos parâmetros da ADA 1995; Bebê-Clínica, 1996.

\begin{tabular}{ccccc}
\hline Tipo de Pasta & $\begin{array}{c}\text { Média de Flúor } \\
\text { ingerido por } \\
\text { escovação (mg) }\end{array}$ & $\begin{array}{c}\text { Frequência de 2 } \\
\text { vezes ao dia }\end{array}$ & $\begin{array}{c}\text { Flúor recomendado } \\
\text { pela ADA }\end{array}$ & $\begin{array}{c}\text { Pode } \\
\text { escovar }\end{array}$ \\
\hline 1000 PPM & 0,21 & 0,42 & 0,50 & SIM \\
& & $0,67 *$ & & NÃO \\
\hline 1100 PPM & 0,23 & 0,46 & 0,50 & SIM \\
\hline 1200 PPM & 0,25 & 0,50 & 0,50 & SĨO \\
\hline 1450 PPM & 0,29 & 0,58 & 0,50 & NÃ̃ \\
\hline 1500 PPM & 0,31 & 0,62 & 0,50 & NÃO \\
\hline & & $0,87^{*}$ & & NÃO \\
\hline
\end{tabular}

OBS: Os valores com * são para as cidades com flúor no sistema de abastecimento das águas. Foi acrescentado $0,25 \mathrm{mg}$ de flúor. 
QUADRO 10 - Frequência de escovação de 2 vezes ao dia para o $3^{\circ}$ grupo em relação a dose ideal proposta por STEWART 1983; Bebê-Clínica, 1996.

\begin{tabular}{|c|c|c|c|c|}
\hline Tipo de Pasta & $\begin{array}{l}\text { Média de Flúor } \\
\text { ingerido por } \\
\text { escovação (mg) }\end{array}$ & $\begin{array}{c}\text { Freqüência de } 2 \\
\text { vezes ao dia }\end{array}$ & $\begin{array}{c}\text { Flúor recomendado } \\
\text { por } \\
\text { STEWART }\end{array}$ & $\begin{array}{l}\text { Pode } \\
\text { escovar }\end{array}$ \\
\hline \multirow[t]{2}{*}{1000 PPM } & 0,21 & 0,42 & 1,06 & SIM \\
\hline & & $0,67 *$ & & SIM \\
\hline \multirow[t]{2}{*}{$1100 \mathrm{PPM}$} & 0,23 & 0,46 & 1,06 & SIM \\
\hline & & $0,71 *$ & & SIM \\
\hline \multirow[t]{2}{*}{$1200 \mathrm{PPM}$} & 0,25 & 0,50 & 1,06 & SIM \\
\hline & & $0,75^{*}$ & & SIM \\
\hline \multirow[t]{2}{*}{1450 PPM } & 0,29 & 0,58 & 1,06 & SIM \\
\hline & & $0,83^{*}$ & & SIM \\
\hline \multirow[t]{2}{*}{1500 PPM } & 0,31 & 0,62 & 1,06 & SIM \\
\hline & & $0,87 *$ & & SIM \\
\hline
\end{tabular}

OBS: Os valores com * são para as cidades com flúor no sistema de abastecimento das águas. Foi acrescentado $0,25 \mathrm{mg}$ de flúor.

QUADRO 11 - Frequência de escovação de 4 vezes ao dia para o $3^{\circ}$ grupo em relação aos parâmetros da ADA 1995; Bebê-Clínica, 1996.

\begin{tabular}{ccccc}
$\begin{array}{c}\text { Tipo de Pasta } \\
\text { Média de Flúor } \\
\text { ingerido por } \\
\text { escovação (mg) }\end{array}$ & $\begin{array}{l}\text { Frequiência de } 4 \\
\text { vezes ao dia }\end{array}$ & $\begin{array}{c}\text { Flúor recomendado } \\
\text { pela ADA }\end{array}$ & $\begin{array}{c}\text { Pode } \\
\text { escovar }\end{array}$ \\
\hline 1000 PPM & 0,21 & 0,84 & 0,50 & NÃO \\
& & $1,09 *$ & & NÃO \\
\hline 1100 PPM & 0,23 & 0,92 & 0,50 & NÃO \\
& & $1,17^{*}$ & & NÃO \\
\hline 1200 PPM & 0,25 & 1,00 & 0,50 & NÃO \\
& & $1,25^{*}$ & & NÃO \\
\hline 1450 PPM & 0,29 & 1,16 & 0,50 & NÃO \\
& & $1,41^{*}$ & & NÃO \\
\hline 1500 PPM & 0,31 & 1,24 & 0,50 & NÃO \\
& & $1,49 *$ & & NÃO
\end{tabular}

OBS: Os valores com * são para as cidades com flúor no sistema de abastecimento das águas. Foi acrescentado 0,25 $\mathrm{mg}$ de flúor.
QUADRO 12 - Frequência de escovação de 4 vezes ao dia para o $3^{\circ}$ grupo em relação a dose ideal proposta por STEWART 1983; Bebê-Clínica, 1996.

\begin{tabular}{|c|c|c|c|c|}
\hline Tipo de Pasta & $\begin{array}{l}\text { Média de Flúor } \\
\text { ingerido por } \\
\text { escovação (mg) }\end{array}$ & $\begin{array}{l}\text { Freqüência de } 4 \\
\text { vezes ao dia }\end{array}$ & $\begin{array}{c}\text { Flúor recomendado } \\
\text { por } \\
\text { STEWART }\end{array}$ & $\begin{array}{l}\text { Pode } \\
\text { escovar }\end{array}$ \\
\hline \multirow[t]{2}{*}{1000 PPM } & 0,21 & 0,84 & 1,06 & SIM \\
\hline & & $1,09 *$ & & $\mathrm{NA} \mathrm{O}$ \\
\hline \multirow[t]{2}{*}{1100 PPM } & 0,23 & 0,92 & 1,06 & SIM \\
\hline & & $1,17^{*}$ & & $\mathrm{NA} O$ \\
\hline \multirow[t]{2}{*}{1200 PPM } & 0,25 & 1,00 & 1,06 & SIM \\
\hline & & $1,25 *$ & & $\mathrm{NA} O$ \\
\hline \multirow[t]{2}{*}{$1450 \mathrm{PPM}$} & 0,29 & 1,16 & 1,06 & NÃO \\
\hline & & $1,41^{*}$ & & $\mathrm{NA} O$ \\
\hline \multirow[t]{2}{*}{$1500 \mathrm{PPM}$} & 0,31 & 1,24 & 1,06 & $\mathrm{NA} O$ \\
\hline & & $1,49^{*}$ & & NÃO \\
\hline
\end{tabular}

OBS: Os valores com * são para as cidades com flúor no sistema de abastecimento das águas. Foi acrescentado $0,25 \mathrm{mg}$ de flúor.

\section{CONCLUSÃO}

O presente estudo nos permite concluir que:

1) para as pastas de até 1200 PPM, a frequência de escovação de 2 vezes ao dia é segura para as populações que moram em cidades sem flúor no Sistema de abastecimeto de água;

2) a segurança de até 2 vezes independe do sistema de avaliação utilizado: ADA 1995, STEWART 1983;

3) as pastas de 1450 e 1500 PPM parecem ser impróprias para o uso em crianças menores de 5 anos de idade, independente da frequência de escovação e da existência ou não de flúor no Sistema de abastecimento de água;

4) este estudo sugere que um melhor controle e, talvez, o uso de soluções fluoretadas de concentração menor que 1000 PPM devam ser introduzidos para crianças menores de 5 anos. 


\section{REFERÊNCIAS BIBLIOGRÁFICAS}

1. CURY, J. A. Dentifrícios fluoretados no Brasil / Fluoride dentifrices in Brazil. Revista Gaúcha de Odontologia. Porto Alegre, v.37, n.2, p. 139-42, Mar/Abr. 1989.

2. EKSTRAND, J. et al. Plasma fluoride concentrations in pre-shool children after ingestion of fluoride tablets and toothpaste. Carie Res., v.17, p.379-84, 1983.

3. EKSTRAND, J. et al. Absorption and retention of dietary and supplemental fluoride by infants. Advances in Dental Reaserd, v.8, p.175-80/ 190201, Jul. 1994.

4. LEVME, R. S. Fluoride and caries prevention: 1 Scientific Rationale. Dental Update, v.18, n.3, p.105-10, Apr. 1991.

5. SHULMAN, J. P. et al. The average daily dose of fluoride: a model based on fluid consumption. Pediatric Dentistry, v.17, n.1, p.13-8, Jan/Feb. 1995.

6. STEWART, R. E. et al. Pediatric Dentistry: scientific foundations and clinical pratice. cap.51, p.772-9, C. V. Mosby Company:London, 1982.

* Pesquisa apresentada nos seguintes eventos científicos:

- IX Jornada Odontológica de Bauru - 14 a 18 de Maio de 1996.

- I Jornada Odontológica de Londrina - 06 a 08 de Junho de 1996.

- IV Semana Acadêmica de Odontologia de Maringá 03 a 06 de Julho de 1996.

\section{* Premiação:}

- 2a colocação na categoria pesquisa científica na I Jornada Odontológica de Londrina - 06 a 08 de Junho de 1996. 